\title{
Recommendations from the Canadian Association of Head and Neck Surgical Oncology for the Management of Head and Neck Cancers during the COVID-19 pandemic
}

Daniel A. O'Connell ${ }^{1,2^{*}}$ (D), Hadi Seikaly ${ }^{1,2^{*}}$, Andre Isaac ${ }^{2}$, Justin Pyne ${ }^{2}$, Robert D. Hart ${ }^{1,3}$, David Goldstein ${ }^{1,4}$, John Yoo ${ }^{1,5}$ and Canadian Association of Head and Neck Surgical Oncology ${ }^{1}$

\begin{abstract}
Introduction: The SARS-CoV-2 virus (COVID19) pandemic has placed extreme pressures on the Canadian Healthcare system. Many health care regions in Canada have cancelled or limited surgical and non-surgical interventions on patients to preserve healthcare resources for a predicted increase in COVID19 related hospital admissions. Also reduced health interventions may limit the risk of possible transmission of COVID19 to other patients and health care workers during this pandemic. The majority of institutions in Canada have developed their own operational mandates regarding access to surgical resources for patients suffering from Head and Neck Cancers during this pandemic. There is a large degree of individual practitioner judgement in deciding access to care as well as resource allocation during these challenging times. The Canadian Association of Head and Neck Surgical Oncology (CAHNSO) convened a task force to develop a set of guidelines based on the best current available evidence to help Head and Neck Surgical Oncologists and all practitioners involved in the care of these patients to help guide individual practice decisions.
\end{abstract}

Main body: The majority of head and neck surgical oncology from initial diagnosis and work up to surgical treatment and then follow-up involves aerosol generating medical procedures (AGMPs) which inherently put head and neck surgeons and practitioners at high risk for transmission of COVID19. The aggressive nature of the majority of head and neck cancer negates the ability for deferring surgical treatment for a prolonged period of time. The included guidelines provide recommendations for resource allocation for patients, use of personal protective equipment for practitioners as well as recommendations for modification of practice during the current pandemic.

(Continued on next page)

\footnotetext{
* Correspondence: dan.oconnnell@ualberta.ca;

hadi.seikaly@albertahealthservices.ca

${ }^{1}$ Canadian Association of Head and Neck Surgical Oncology (CAHNSO), 1E4

8440112 Street NW, Edmonton, AB T6G 2B7, Canada

Full list of author information is available at the end of the article
}

\section{$\triangle B M C$}

(c) The Author(s). 2020 Open Access This article is licensed under a Creative Commons Attribution 4.0 International License, which permits use, sharing, adaptation, distribution and reproduction in any medium or format, as long as you give appropriate credit to the original author(s) and the source, provide a link to the Creative Commons licence, and indicate if changes were made. The images or other third party material in this article are included in the article's Creative Commons licence, unless indicated otherwise in a credit line to the material. If material is not included in the article's Creative Commons licence and your intended use is not permitted by statutory regulation or exceeds the permitted use, you will need to obtain permission directly from the copyright holder. To view a copy of this licence, visit http://creativecommons.org/licenses/by/4.0/ The Creative Commons Public Domain Dedication waiver (http://creativecommons.org/publicdomain/zero/1.0/) applies to the data made available in this article, unless otherwise stated in a credit line to the data. 


\section{(Continued from previous page)}

\section{Conclusion:}

1. Enhanced triaging should be used to identify patients with aggressive malignancies. These patients should be prioritized to reduce risk of significant disease progression in the reduced resource environment of COVID19 era.

2. Enhanced triaging including aggressive pre-treatment COVID19 testing should be used to identify patients with high risk of COVID19 transmission.

3. Enhanced personal protective equipment (PPE) including N95 masks and full eye protection should be used for any AGMPs performed even in asymptomatic patients.

4. Enhanced PPE including full eye protection, N95 masks and/or powered air purifying respirators (PAPRs) should be used for any AGMPs in symptomatic or presumptive positive COVID 19 patients.

Keywords: COVID-19, SARS-Cov-2, Global pandemic, Head and neck oncology, Head and neck surgery, Clinical practice guideline

\section{Introduction}

The emergence of the SARS-CoV-2 virus (COVID19) as a novel virus causing severe respiratory illness was first described in December 2019 in Wuhan China. Since that time the World Health Organization (WHO) has declared COVID19 a pandemic (Mar 112,020) and health authorities have been mobilizing to accommodate a predicted surge in patients who require hospital and/or intensive care unit admission due to the direct effects of the virus [1]. The reality of oncologic surgery is that any significant delay in time to treatment will often have a deleterious effect on survival and functional outcomes for the individual patient. This makes managing head and neck cancer patients in the pandemic era much more challenging due to resource limitations placed on the healthcare system by COVID19. In the 2003 Severe Acute Respiratory Syndrome (SARS) pandemic, significant limitations were placed on surgical resource access in Ontario which did have a long term effect both on patient care as well as economic impact on the healthcare system once the pandemic passed and the backlog of surgical patients placed an increased strain on the system resources [2].

Head and neck surgical oncology is particularly challenging in the COVID19 era as all aspects of patient care from initial consultation, to surgical treatment, then post-treatment follow-up involve some degree of AGMPs in standard practice. The upper aerodigestive tract includes the nasal cavities, nasopharynx, oral cavity, oropharynx, hypopharynx, larynx, and trachea. This tract is a zone of intense COVID-19 viral replication [1]. There is growing evidence that personnel who perform procedures in the upper aerodigestive tract, and in particular otolaryngologists Head and Neck Surgeons are at high risk of not only becoming exposed to COVID-19, but also developing severe illness from the virus $[3,4]$. In an anecdotal report from Wuhan, it was noted that 14 personnel became may have been infected from a single endoscopic trans-sphenoidal pituitary case, including every OR staff member that was involved in the case $[5,6]$. Europe has seen the same high infection rate of otolaryngologists, as reported by intensive care units across the region [7]. There was recently a report of four otolaryngologists in the UK having been infected, two of which are intubated and in critical condition in the ICU, after having contracted COVID-19 from asymptomatic patients [8]. Reliable reports have documented active transmission in asymptomatic cases [6]. The increased risk of contracting COVID-19 in these procedures is thought to be due to the high viral load in the upper respiratory tract [9]. Not only this, but persons who are exposed to high viral loads, such as during surgery as opposed to contracting the virus in the community, are thought to suffer more severe illness due to the release of cytokine storms in these settings [10].

This new and emerging information has led to several specialty societies and health authorities making recommendations on the use of PPE in procedures that are considered aerosol-generating (aerosol generating medical procedures or AGMPs), where standard contact and droplet precautions are not sufficient to protect against aerosolized viral particles. Whereas many of these recommendations vary in the details, all published criteria in the literature now support the use of N95 masks and associated aerosolized droplet precautions with all aerosol-generating medical procedures, regardless of COVID-19 testing. Many guidelines go much farther, recommending PAPRs for all such cases $[4,11]$. The question of whether this should be enacted relies on three central issues:

1. The expected rate of community viral burden in the province of practice.

2. The rate of asymptomatic infection. 
3. The reliability of COVID-19 testing in asymptomatic patients.

With respect to the first issue, we know that community transmission of COVID-19 is rising across Canada, and is now responsible for more than half of infections in the country [12]. Projections vary widely, but according to the federal health minister, "between 30 and 70 percent of Canadians could become infected with coronavirus" [13]. Countries that did not prepare for this scenario are now facing such consequences, including Italy which is battling a high rate of health worker infections and COVID-related deaths.

With respect to the second issue, emerging data shows that asymptomatic infections may be much more common than previously thought. During the Centers for Disease Control, (CDC) investigation of the Diamond Princess cruise ship outbreak, $46.5 \%$ of infected individuals were asymptomatic at the time of testing, and $17.9 \%$ of those infected never developed symptoms [14]. This is in alignment with findings in children, which show that more than $15 \%$ of patients have asymptomatic infection [15]. There is also ample data to show that active transmission of the virus occurs in asymptomatic persons [16].

Finally, current methods of testing for the COVID-19 virus are not validated for use in asymptomatic persons. Departments of Public Health and the CDC have repeatedly warned about the false negative (and false positive) rate of nasal swabs in asymptomatic patients [16-18]. Although a positive COVID-19 swab in an asymptomatic patient can be useful, a negative swab cannot be relied on to be accurate.

The current COVID19 pandemic makes treating head and neck cancers even more challenging in terms of triaging patients and allocating limited surgical resources. Surgical oncologists worldwide have published recommendations about application and utilization of surgical resources in these challenging times [19-28]. Head and neck surgeons have the difficult task of following chronically ill patients while at the same time mitigating the risk of person to person contact $[25,29]$. In doing so, head and neck cancer survivors may be impacted negatively in terms of quality of life as well as disease recurrence detection [23]. Further, those with tracheostomies or laryngeal stomas are at increased risk of transmission and spread of COVID-19 [24].

In summary, we can conclude and/or infer the following from the available data:

1. Personnel who are involved in aerosol-generating medical procedures, in particular otolaryngologists, are at high risk of contracting COVID-19 AND potentially suffering severe or fatal illness from the disease $[3,4,8,19,28,29]$.
2. Standard contact and droplet precautions are not sufficient for protecting against COVID-19 in these circumstances $[3,4,11,19,28]$.

3. There is (and/or soon will be) an increasing burden of the novel coronavirus in the general population $[1,6,12]$.

4. A significant proportion of COVID-19 infections are asymptomatic or lack symptoms of upper respiratory tract infection, and these persons can transmit the virus and infect others $[16,17]$.

5. A negative COVID-19 swab cannot rule out infectivity in asymptomatic persons $[16,17]$.

6. If you consider an infection rate of only $30 \%$ in the general population, with up to $15 \%$ of COVID-19 positive patients being asymptomatic, then 1 in 20 patients undergoing surgery may be unknowingly COVID-19 positive, potentially exposing the entire team to high risk of infection without proper precautions.

\section{Referrals}

b. Outpatient, clinic, and office consultations should be limited to urgent or emergent referrals

c. A robust triage referral system should be in place to screen for referrals with prioritization of those with a high risk of malignancy/cancer - these patients would then be deemed urgent referrals

d. Referrals with low likelihood of malignancy or known benign disease should be deferred with records kept for the purposes of later recall where resources and appropriateness allow

e. Virtual / telephone consultation should be considered for all referrals with a risk of malignancy to better ascertain severity and to guide need for face to face consultations.

f. Restrict all patient face to face patient assessments to urgent and emergent interactions.

g. Patients who are at higher risk for adverse outcomes following COVID-19 infection (age $>70$ years, known high risk comorbidities, frailty) who meet high risk cancer criteria should be prioritized in a way that minimizes their time in hospital / clinical environments with any elevated risk of COVID 19 exposure

\section{Diagnostic work-up}

h. All patients must undergo clinical screening prior to entering the assessment/treatment area. Minimum screening should include screening questionnaire, travel history, COVID-19 contact risk assessment and body temperature reading. 
Screening should follow local or regional guidelines where available.

i. Nasopharyngoscopy, rigid nasal endoscopy, flexible laryngoscopy are considered Aerosol Generating Medical Procedures (AGMPs) and appropriate PPE should be worn by providers during these procedures. See - https://www.entcanada.org/wp-content/uploads/ NCAL-HN-Oncologic-Surgery-in-COVID-Era_v3.pdf

j. Upper aerodigestive endoscopy should only be performed when absolutely necessary. Staff must not use atomizers for anesthesia and decongestion when performing transnasal endoscopy on patients.

k. COVID negative or unknown status and asymptomatic patients for consultation +/performing transnasal endoscopy:

1. The patient should only be scoped once. Only the treating physician should perform the procedure.

2. PPE should include scrubs, water impermeable gown, N95 mask, face shield or other eye protection, and gloves.

3. The use of video towers is recommended.

1. COVID positive or presumed positive

(symptomatic) patients for consultations +/performing transnasal endoscopy:

1. The examination should be performed in room with negative pressure.

2. Only treating physician or a senior learner should perform the procedure.

3. PPE should include scrubs, water impermeable gown, surgical hood, full face shield, and double gloves and N95 mask or Powered Air Purifying Respirator (PAPR)

Appropriate donning and doffing protocols are critical and must be followed when using PPE. An appropriately fit-tested N95 respirator is equally important.

m. Limit diagnostic work up including biopsies, and diagnostic imaging to those cases with a high risk of malignancy

n. Diagnostic imaging requests for patients with a high risk of malignancy should be reduced to the minimum modality(ies) required for safe oncologic treatment decision making.

o. Diagnostic work up including biopsies and diagnostic imaging for cases with low risk of malignancy should be deferred with records kept to initiate work up if required at a later date

p. Ensuring appropriate Personal Protective Equipment (PPE) is available for all health care providers interacting with patients - see https:// www.entcanada.org/wp-content/uploads/NCALHN-Oncologic-Surgery-in-COVID-Era_v3.pdf

\section{Multi-disciplinary tumor team (MDT) function}

q. MDT / tumor board meetings that require in person interactions that violate social distancing recommendations $(<2 \mathrm{~m}$ space between all individuals) should be postponed indefinitely.

r. MDT / tumor board meetings should be converted (where possible) into virtual formats to enable continued function at normal intervals and continued attendance by all required members.

\section{Surgical management in the COVID-19 era}

s. Surgical treatment of Head \& Neck Cancer should be prioritized locally to ensure higher risk cases (those with high likelihood of rapid progression, increased risk of death) are receiving priority treatment.

t. As the timeline of duration of the COVID 19 epidemic is unknown, expedition of the surgical management of cases in which a worse outcome is expected if surgery is delayed more than $4-6$ weeks including [20, 21]:

1. Squamous cell carcinoma (SCCA) of the oral cavity, oropharynx, larynx, hypopharynx

2. Cancers with impending airway compromise

3. Papillary thyroid cancer with impending airway compromise, rapidly growing, bulky disease

4. High grade or progressive salivary cancer

5. T3/T4 melanoma

6. Rapidly progressing cutaneous SCCA with regional disease

7. Salvage surgery for recurrent or persistent disease

8. High grade sinonasal malignancy lacking equivalently efficacious non-surgical treatment

u. PPE during Head \& Neck Surgical interventions:

All recommendations listed below are based on best available current evidence. Further information can be found in the following:

1. https://www.entcanada.org/wp-content/uploads/ NCAL-HN-Oncologic-Surgery-in-COVID-Era v3.pdf

2. https://www.entcanada.org/wp-content/uploads/ NCAL-HN-Oncologic-Surgery-in-COVID-Era_ v3.pdf

3. https://www.entuk.org/covid-19

4. http://www.asohns.org.au/about-us/news-andannouncements/latest-news?article $=78$

5. https://www.entcanada.org/news-events/covid-1 9-alerts/ 
6. https://www.ncbi.nlm.nih.gov/pmc/articles/ PMC7136881/

7. https://www.baoms.org.uk/_userfiles/pages/files/ professionals/covid_19/baoms_baos_covid_ advice_update_25_march_2020_final.pdf

v. COVID testing for surgical patients where available is supported by CAHNSO especially for procedures that require manipulation of the upper aerodigestive tract.

1. Patients that test positive should have their surgery canceled if not urgent or emergent and get rebooked when they test negative.

2. Patients that test negative should have their surgery booked and PPE precautions should be instituted as listed below (Diagnsotic work- up recommendations $3 \mathrm{a}-\mathrm{c}$ ), as the limited sensitivity and negative predictive value of testing in asymptomatic patients does not rule out an infectious state.

w. Surgery for COVID unknown or negative patients that requires manipulation of the upper aerodigestive tract:

1. The operating team should be reduced to essential personnel.

2. The surgical team PPE should include scrubs, gown, N95 masks, surgical hood, face shield, and double gloves or PAPR, scrubs, gown, and double gloves.

$\mathrm{x}$. Surgery for COVID unknown or negative patients that does not require manipulation of the upper aerodigestive tract.:

1. PPE as per local or regional health authority recommendations.

y. Surgery for COVID positive patients that includes manipulation of the upper aerodigestive tract.

1. These cases should be performed on an emergent basis only.

2. These cases should be performed in a dedicated operating room, following local or regional health authority protocols.

3. The operating team should be reduced to essential personnel.

4. The surgical team PPE should include: PAPR scrubs, gown, and double gloves.

Appropriate donning and doffing protocols are critical and must be followed when using PPE. An appropriately fit-tested N95 respirator is equally important.

\section{Follow-up}

z. All non-urgent follow ups should be postponed with records kept for the purposes of later recall where resources and appropriateness allow aa. Efforts should be made to maximize the utilization of virtual / telephone follow-ups where appropriate for head and neck cancer follow-ups

bb. In person patient assessments should be limited to urgent or emergent issues where in person evaluation is required to proceed with treatment decision making.

cc. All urgent or emergent follow up interactions should follow the same guidelines outlined in sections 2 (referrals) and 3 (diagnostic work-up).

\section{Clinical trials}

dd. Prioritize support for patients currently on clinical trials in active treatment

ee. Consider stopping recruitment into clinical trials where issues arise with patient safety or capacity (resource impact in COVID 19 era)

ff. Local, regional and national guidance should be sought to help manage existing clinical trials for the management of head and neck cancers - https:// www.canada.ca/en/health-canada/services/drugshealth-products/drug-products/announcements/ management-clinical-trials-during-covid-19pandemic.html

\section{Acknowledgements}

The authors would like to acknowledge health professionals both and Canada and internationally who continue to show courage and leadership in providing health care services to those in need during the current pandemic.

\section{Declarations}

The authors have no competing interests to declare.

\section{Authors' contributions}

D.A. O'Connell - a. substantial contributions to conception and design an analysis and interpretation of data; $b$. drafting the article and revising it critically for important intellectual content; c. final approval of the version to be submitted for publication, and d. agreement to be accountable for all aspects of the work in ensuring that questions related to the accuracy or integrity of any part of the work are appropriately investigated and resolved. H. Seikaly - a. substantial contributions to conception and design an analysis and interpretation of data; b. drafting the article and revising it critically for important intellectual content; c. final approval of the version to be submitted for publication, and d. agreement to be accountable for all aspects of the work in ensuring that questions related to the accuracy or integrity of any part of the work are appropriately investigated and resolved. A. Isaac - a. substantial contributions to conception and design an analysis and interpretation of data; $b$. drafting the article and revising it critically for important intellectual content; c. final approval of the version to be submitted for publication, and d. agreement to be accountable for all aspects of the work in ensuring that questions related to the accuracy or integrity of any part of the work are appropriately investigated and resolved. J. Pyne - a. substantial contributions to conception and design an analysis and interpretation of data; b. drafting the article and revising it critically for important intellectual content; $c$. final approval of the version to be submitted for publication, and d. agreement to be accountable for all aspects of the work in ensuring that questions related to the accuracy or integrity of any part of the work are appropriately investigated and resolved. R.D. Hart - a. substantial contributions to conception and design an analysis and interpretation of data; b. revising the article critically for important intellectual content; c. final approval of the version to be submitted for publication, and $\mathrm{d}$. agreement to be accountable for all aspects of the work 
in ensuring that questions related to the accuracy or integrity of any part of the work are appropriately investigated and resolved. D. Goldstein - a. substantial contributions to conception and design an analysis and interpretation of data; b. revising the article critically for important intellectual content; $c$. final approval of the version to be submitted for publication, and $\mathrm{d}$. agreement to be accountable for all aspects of the work in ensuring that questions related to the accuracy or integrity of any part of the work are appropriately investigated and resolved. J. Yoo - a. substantial contributions to conception and design an analysis and interpretation of data; b. revising the article critically for important intellectual content; c. final approval of the version to be submitted for publication, and d. agreement to be accountable for all aspects of the work in ensuring that questions related to the accuracy or integrity of any part of the work are appropriately investigated and resolved. Canadian Association of Head and Neck Surgical Oncology - a. substantial contributions to conception and design an analysis and interpretation of data; b. drafting the article and revising it critically for important intellectual content; c. final approval of the version to be submitted for publication, and d. agreement to be accountable for all aspects of the work in ensuring that questions related to the accuracy or integrity of any part of the work are appropriately investigated and resolved.

\section{Funding}

None.

\section{Availability of data and materials}

Available upon request.

\section{Ethics approval and consent to participate}

Not applicable.

\section{Consent for publication}

All authors consent to the publication of the manuscript submitted.

\section{Competing interests}

The authors have no relevant competing interests to declare.

\section{Author details}

${ }^{1}$ Canadian Association of Head and Neck Surgical Oncology (CAHNSO), 1 E4 8440112 Street NW, Edmonton, AB T6G 2B7, Canada. ²Division of Otolaryngology - Head \& Neck Surgery, University of Alberta, Edmonton, AB, Canada. ${ }^{3}$ Division of Otolaryngology, University of Calgary, Calgary, AB, Canada. ${ }^{4}$ Department of Otolaryngology - Head \& Neck Surgery, University of Toronto, Toronto, ON, Canada. ${ }^{5}$ Department of Otolaryngology - Head \& Neck Surgery, University of Western Ontario, London, ON, Canada.

\section{Received: 5 May 2020 Accepted: 6 July 2020}

Published online: 29 July 2020

\section{References}

1. World Health Organization. Rolling updates on coronavirus disease (COVID19). (https://www.who.int/emergencies/diseases/novel-coronavirus-2019/ events-as-they-happen). Accessed 29 Mar 2020.

2. Health NACOSaP. Learning from SARS: renewal of public health in Canada. 2003.

3. Chan JYK, Wong EWY, Lam W. Practical aspects of Otolaryngologic clinical services during the 2019 novel coronavirus epidemic. JAMA Otolaryngol Neck Surg. 2020. https://doi.org/10.1001/jamaoto.2020.0488.

4. Patel ZM, Hwang PH, Nayak J V, et al. Stanford University School of Medicine Statement on the COVID-19 Pandemic and Guidelines for Otolaryngology-Head and Neck Surgery. https://www.docdroid.net/AyUBOji/ covid-19-information.pdf. Published 2020.

5. China Newsweek. China Newsweek. View.inews.qq.com/a/20200125A07TT2 00? uid=\&devid=BDFE70CD-5BF1-4702-91B7-329F20A6E839\&qimei= bdfe70cd-5bf1-4702-91b7-329f20a6e839. Published 2020.

6. Chang D, Xu H, Rebaza A, Sharma L, Dela Cruz CS. Protecting health-care workers from subclinical coronavirus infection. Lancet Respir Med. 2020;8(3): e13. https://doi.org/10.1016/\$2213-2600(20)30066-7.

7. Che C. Europe's doctors repeat errors made in Wuhan, China medics say. Bloomberg News. https://www.bloomberg.com/news/articles/2020-03-17/ europe-s-doctors-getting-sick-like-in-wuhan-chinese-doctors-say?fbclid=
IwAR2ds90WRxQuMHAuy5Gb7|tqUGMZNSojVNtFmq3zzcSLb_ b09aGYr7URxal. Published 2020.

8. Coronavirus: Two NHS medics on ventilators after contracting COVID-19 from patients. Sky News. https://news.sky.com/story/coronavirus-two-nhsmedics-on-ventilators-after-contracting-covid-19-from-patients-11961531. Accessed 3 Apr 2020.

9. Zou L, Ruan F, Huang M, et al. SARS-CoV-2 viral load in upper respiratory specimens of infected patients. N Engl J Med. 2020;382(12):1177-9. https:// doi.org/10.1056/NEJMc2001737.

10. Mehta P, McAuley DF, Brown M, et al. COVID-19: consider cytokine storm syndromes and immunosuppression. Lancet (London, England). 2020;0(0). https://doi.org/10.1016/S0140-6736(20)30628-0.

11. Magennis P, Guidance PPE. For patients with emergency oropharyngeal and nasopharyngeal conditions whose COVID status is unknown. British Association of Oral and Maxillofacial Surgeons. https://mcusercontent.com/e386d81be4a76 bada89909666/files/2461d4d7-eea2-428a-b78b-8bc34409f3b1/BAOMS_ENT_ COVID_Advice_Update_25_March_2019_Final_1_.pdf. Accessed 3 Apr 2020.

12. Epidemiological summary of COVID-19 cases in Canada. Public Health Agency of Canada. https://www.canada.ca/en/public-health/services/ diseases/2019-novel-coronavirus-infection/health-professionals/ epidemiological-summary-covid-19-cases.html. Accessed 3 Apr 2020.

13. Weeks C. Between 30 and 70 per cent of Canadians could become infected with coronavirus, Patty Hajdu says. The Globe and Mail https://www. theglobeandmail.com/canada/article-between-30-and-70-per-cent-ofcanadians-could-be-infected-with/. Accessed 3 Apr 2020.

14. CDC Cruise Ship Response Team, California Department of Public Health COVID-19 Team, Solano County COVID-19 Team. Publich health responses to COVID-19 outbreaks on cruiseships - worldwide, February-March 2020. Centres Dis Control Prev Morb Mortal Wkly Rep 69. https://www.cdc.gov/ mmwr/volumes/69/wr/pdfs/mm6912e3-H.pdf. Accessed 3 Apr 2020.

15. Lu X, Zhang L, Du H, et al. SARS-CoV-2 Infection in Children. N Engl J Med. March 2020:NEJMc2005073. https://doi.org/10.1056/NEJMc2005073.

16. Krieger L. Coronavirus false test results: with the push to screen come questions of accuracy. The Mercury News https://www.mercurynews.com/2 020/03/19/coronavirus-false-test-results-with-the-push-to-screen-comequestions-of-accuracy/. Accessed 3 Apr 2020.

17. Hao Q, Wu H, Wang Q. Difficulties in False Negative Diagnosis of Coronavirus Disease 2019: A Case Report. Infect Dis - Prepr. March 2020. https://doi.org/10.21203/RS.3.RS-17319/N1.

18. Xie X, Zhong Z, Zhao W, Zheng C, Wang F, Liu J. Chest CT for typical 2019nCoV pneumonia: relationship to negative RT-PCR testing. Radiology. 2020; 200343. https://doi.org/10.1148/radiol.2020200343.

19. Schultz P, Morvan JB, Fakhry N, Morinière S. French consensus regarding precautions during tracheostomy and post-tracheostomy care in the context of COVID-19 pandemic. Eur Ann Otorhinolaryngol Head Neck Diseases. https://doi.org/10.1016/j.anorl.2020.04.006.

20. Fakhry N, Schultz P, Morinière S, Breuskin I, Bozec A. French consensus on management of head and neck cancer surgery during COVID-19 pandemic. Eur Ann Otorhinolaryngol Head Neck Diseases. https://doi.org/10.1016/j. anorl.2020.04.008.

21. Qadan, M., Hong, T. S., Tanabe, K. K., Ryan, D. P., \& Lillemoe, K. D. A Multidisciplinary Team Approach for Triage of Elective Cancer Surgery at the Massachusetts General Hospital During the Novel Coronavirus COVID-19 Outbreak. Ann Surg 1. https://doi.org/10.1097/SLA.0000000000003963.

22. Topf, M. C., Shenson, J. A., Holsinger, F. C., Wald, S. H. A Framework for Prioritizing Head and Neck Surgery during the COVID-19 Pandemic. Head Neck, hed.26184. https://doi.org/10.1002/hed.26184.

23. Adjei Boakye, E., Jenkins, W., Sharma, A. Disproportionate impact of COVID19 pandemic on head and neck cancer survivors. Head Neck, hed.26170. https://doi.org/10.1002/hed.26170.

24. Kligerman, M. P., Vukkadala, N., Tsang, R. K. Y., Sunwoo, J. B. Managing head and neck cancer patients with tracheostomy or laryngectomy during the COVD-19 pandemic. Head Neck, hed.26171. https:/doi.org/10.1002/hed.26171.

25. Prasad, A., Carey, R. M., Rajasekaran, K. Head and neck virtual medicine in a pandemic era: Lessons from COVID-19. Head Neck, hed.26174. https://doi. org/10.1002/hed.26174.

26. Kowalski LP, Sanabria A, Ridge JA, Ng WT. COVID-19 pandemic: effects and evidence-based recommendations for otolaryngology and head and neck surgery practice. Head Neck. https://doi.org/10.1002/hed.26164.

27. Magennis, P. Guidance PPE for patients with emergency oral and dental problems of unknown COVID Status. Retrieved from https://www.baoms. 
org.uk/_userfiles/pages/files/professionals/covid_19/baoms_baos_covid_ advice_update_25_march_2020_final.pdf. Accessed 3 Apr 2020.

28. Pichi, B., Mazzola, F., Bonsembiante, A., Petruzzi, G. CORONA-steps for tracheotomy in COVID-19 patients: a staff-safe method for airway management. Oral Oncol 104682. https://doi.org/10.1016/J. ORALONCOLOGY.2020.104682.

29. Liu, Z., Zhang, Y., Wang, X., Zhang, D. Recommendations for Surgery During the Novel Coronavirus (COVID-19) Epidemic. Indian J Surg, 1-5. https://doi. org/10.1007/s12262-020-02173-3.

\section{Publisher's Note}

Springer Nature remains neutral with regard to jurisdictional claims in published maps and institutional affiliations.

Ready to submit your research? Choose BMC and benefit from:

- fast, convenient online submission

- thorough peer review by experienced researchers in your field

- rapid publication on acceptance

- support for research data, including large and complex data types

- gold Open Access which fosters wider collaboration and increased citations

- maximum visibility for your research: over $100 \mathrm{M}$ website views per year

At $\mathrm{BMC}$, research is always in progress.

Learn more biomedcentral.com/submissions 